\title{
Chow Chow
}

National Cancer Institute

\section{Source}

National Cancer Institute. Chow Chow. NCI Thesaurus. Code C53851.

The Chow Chow has a dense, furry, and profuse coat. Its two most distinctive features are its blue-black tongue and its almost straight hind legs, which causes it to walk rather stilted. Its dense furry coat is profuse and comes in two varieties, smooth coat and rough coat. The most common colors are solid red, black, blue, cinnamon and cream, but it can also come in tan, gray, or (rarely) white. The ears are small and rounded and there is a large ruff behind the head, which gives it a lion like appearance. Height: 18-22 inches (46-56 cm.) Weight: 45-70 pounds (20-32 kg.) 